\title{
PROCESSO DE EXPANSÃO URBANA DE CAMPINA GRANDE- PB SOB A ÓTICA DA REGIÃO SUDOESTE
}

Davi Mendes Agra

e24257

\section{RESUMO}

A urbanização da região sudoeste da cidade de Campina Grande, no estado da Paraíba, teve destaque a partir da implantação de investimentos públicos e privados em infraestrutura e empreendimentos destinados a habitações de interesse social. Essa pesquisa buscou refletir como ocorreu o processo nos últimos vinte anos, destacando a importância das legislações urbanísticas, sobretudo do plano diretor no reflexo dinâmico ocupacional e social resultante dessa expansão. Foi utilizada a metodologia exploratória bibliográfica e descritiva. Os resultados alcançados evidenciaram que a luta pelo direito à moradia digna refletem um cenário de avanços urbanísticos, valorização do solo e quão ainda essa região pode expandirse com a nova revisão do plano diretor.

Palavras-chave: Urbanização; Expansão; Legislações urbanísticas.

\section{ASBTRACT}

The urbanization of the southwestern region of the city of Campina Grande, in the state of Paraíba, was highlighted from the implementation of public and private investments in infrastructure and developments for housing of social interest. This research sought to reflect how the process occurred in the last twenty years, highlighting the importance of urban legislation, especially the master plan in the dynamic occupational and social reflection resulting from this expansion. The bibliographic and descriptive exploratory methodology was used. The results showed that the struggle for the right to decent housing reflects a scenario of urban advances, land valuation and how still this region can expand with the new revision of the master plan.

Keywords: Urbanization; Expansion; Urban legislation.

\section{INTRODUÇÃO}

A relevância em estudar o processo da acelerada expansão urbana e os desdobramentos provocados por ela na região sudoeste do município de Campina Grande-PB, dar-se pela necessidade em entender os princípios da formação socioespacial e econômica dessa área da cidade a partir da implantação de infraestrutura urbana e empreendimentos habitacionais, sobretudo pela significância das políticas públicas e legislações urbanísticas norteadoras do parcelamento, uso e ocupação do solo, principalmente no que tange ao direito à cidade e seu reflexo nos dias atuais.

Destaca-se no presente estudo a ocupação territorial da região sudoeste campinense ocorrida entre 1960 e 1980 com o surgimento dos programas federais de melhorias habitacionais e desenvolvimento urbano, a fim de compreender as modificações e reestruturações espaciais ocorridas nas décadas posteriores, com o surgimento de legislações municipais e elucida-se a importância das suas revisões nesse processo.

Busca-se analisar também os parâmetros da centralidade, segregação e gentrificação, e como esses fatores refletem na qualidade de vida dos moradores, pelos reflexos dos sólidos investimentos na requalificação da infraestrutura advindos dos setores públicos e privados, 
sobretudo pela localização privilegiada dessa região, que margeia duas vias arteriais que ligam a outros municípios, a BR 230 e a BR 104, tendo em vista que essa região possuía um perfil exclusivamente residencial unifamiliar, passando a possuir grandes empreendimentos com edificações multifamiliares, condomínios residenciais fechados de padrão social elevado, além de usos mistos do solo com edificações destinadas a comércio, serviços e indústrias.

Sendo assim, o presente trabalho, cujo aspecto metodológico aplicado foi de caráter básico, com objetivos exploratórios, pesquisa bibliográfica e descritiva, tem a intenção de apresentar reflexões a partir do processo dinâmico da expansão urbana na região sudoeste da cidade de Campina Grande-PB nas últimas décadas e como esse processo reflete nos aspectos políticos, sociais, econômicos e culturais, levando em consideração a relevância do direito à cidade e seu antagonismo.

O contexto exposto será elucidado em três seções, demonstrando como se deu o processo de urbanização no Brasil e na região Nordeste, seguido da cidade de Campina Grande - PB, com enfoque na expansão da região sudoeste. A segunda seção enfatizará a importância do surgimento dos empreendimentos de habitação de interesse social e sua influência na organização territorial nessa região. A terceira e última seção fará uma análise socioespacial desse processo no que diz respeito aos aspectos de centralidade, segregação e gentrificação

\section{PRIMÓRDIOS DO PROCESSO dE URBANIZAÇÃO NO BRASIL E NA REGIÃO NORDESTE}

A partir da revolução industrial, a população nas grandes cidades vem crescendo exponencialmente através do êxodo rural, da ideia das transformações econômicas e de acessos a bens postos nos centros urbanos. No Brasil, o processo de expansão urbana iniciouse partir dos anos 50 , com a industrialização e a população, até então predominantemente rural, passou a crescer nas áreas urbanas das grandes capitais brasileiras. No que se refere ao ordenamento nesse processo de ocupação, as políticas públicas passaram a ter um papel fundamental para evitar problemas de caráter socioambiental. (GOMES, 2012).

Com a globalização, o território brasileiro passa por notável transformação. Mudam as dinâmicas. As dinâmicas demográfica, urbana e ambiental, além de social e econômica. As metrópoles crescem menos do que as cidades de porte médio (100.000 a 500.000 hab.) tanto em habitantes quanto em PIB. O processo de urbanização se interioriza sob influência do agronegócio. Não há um deslocamento do centro de poder econômico situado no Sudeste, mas os dados mostram que esta região cresce menos se comparada com todas as outras. (MARICATO, 2012, p.01.)

A urbanização no Nordeste iniciou-se no período colonial e caracterizou-se de forma e período distintos das demais regiões brasileiras, em virtude do fato abrigar as primeiras localidades colonizadas e onde se instalaram as principais atividades econômicas. 
Estabeleceu-se, primeiramente, a cultura da cana-de-açúcar, consolidando a formação do chamado "Nordeste Açucareiro", posteriormente outros produtos, como o algodão, favorecendo o crescimento de cidades como Salvador e Recife. (PENA, 2015).

\subsection{CARACTERIZAÇÃo DA ÁREA DE ESTUdo E SEU DESENVOLVIMENTO URBANÍSTICO}

O município de Campina Grande situa-se no Planalto da Borborema, agreste do Estado da Paraíba - Brasil, a uma altura de aproximadamente de 550 metros acima do nível do mar e no ponto de latitude 7013'11" sul e de longitude 35052'31" oeste (figura 01 ). De acordo com os dados fornecidos pelo Instituto Brasileiro de Geografia e Estatística (IBGE), possui 411.807 habitantes [2020] e área territorial de $591,658 \mathrm{~km}^{2}$ [2019].

Figura 01 - Mapa da cidade de Campina Grande e suas regiões

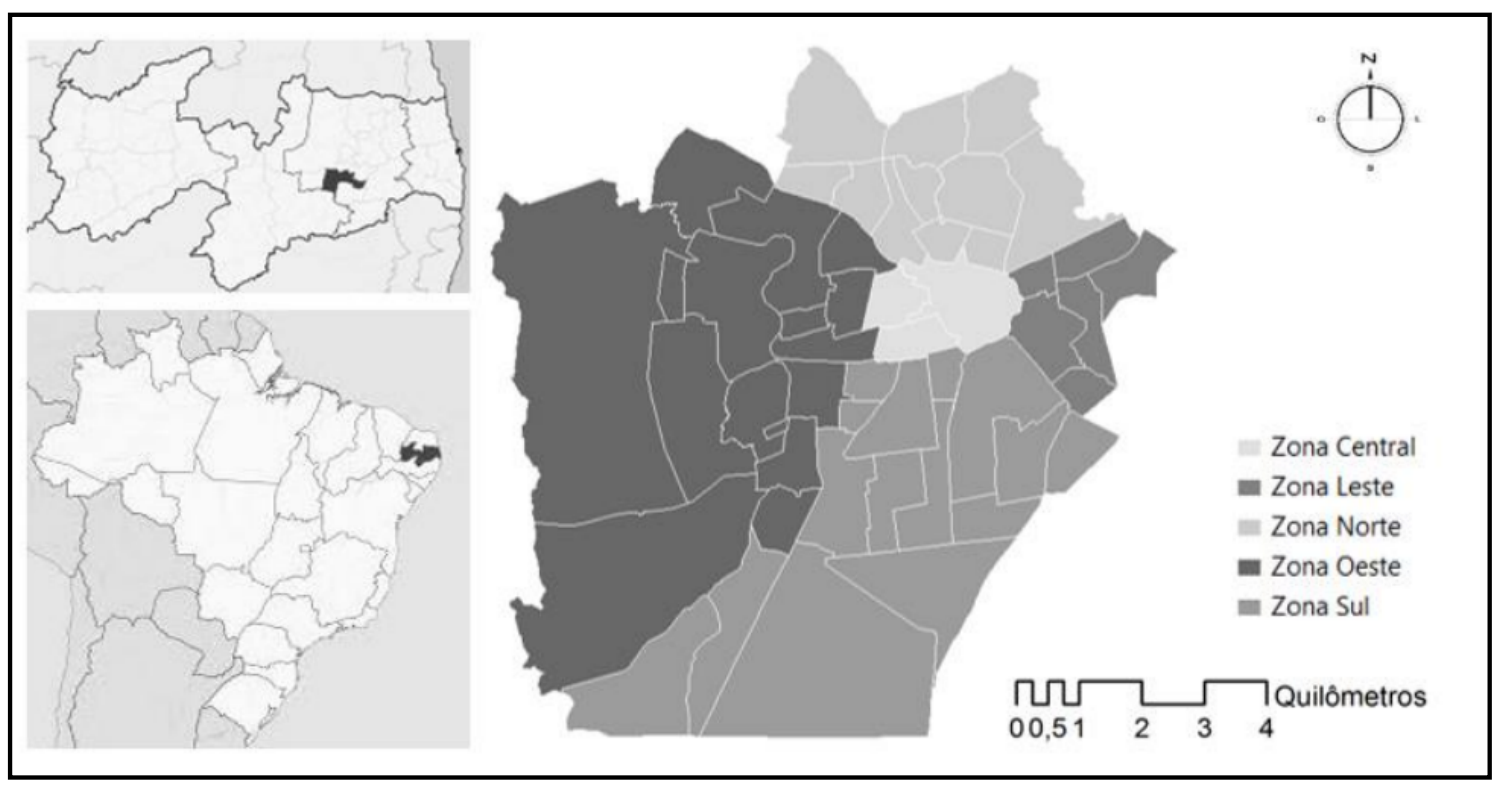

Fonte: (BARROS FILHO; SILVA JÚNIOR; BRITO, 2016)

Desde os seus primórdios, a ascensão urbana de Campina Grande já era evidente, evoluiu consideravelmente em um período de cem anos e passou do então sítio Barroco para categoria de vila entre 1678 e 1790. A primeira feira foi advinda do comércio de farinha e marcou o processo de urbanização da recém-batizada Vila Nova da Rainha, sua localização privilegiada (na Serra da Borborema) foi um dos fatores preponderantes para essa ascensão. Começou a comercializar animais, destacando os bois como meio rudimentar de transporte, passando a ser produto principalmente pelo comércio do couro. (BARROS FILHO; SILVA JÚNIOR; BRITO, 2016)

O desenvolvimento urbano e populacional crescia e em 1828, foi construído na Vila Nova da Rainha, o açude que hoje é conhecido como o Açude Velho, grande cartão postal. 
Em 11 de outubro de 1864, de acordo com a Lei Provincial no 137, Campina Grande se eleva à categoria de Cidade e apesar de todo o desenvolvimento comercial, o aspecto urbano não mudou nos 30 anos subsequentes. Em março de 1904, a mobilidade urbana começou a ganhar destaque com a chegada dos primeiros carros e ônibus.(PENA, 2015).

Em 1907, a linha férrea de Recife começa a ser expandida, ligando a capital do estado vizinho à Campina Grande, ajudando a cidade no comércio e no escoamento do algodão, passando esse produto a ser base para a economia campinense no início do século $\mathrm{XX}$, sendo entre 1930 e 1945 um período próspero nos âmbitos sociocultural e urbanístico, devido influência europeia vinda da capital pernambucana. Com a reorganização do espaço urbano, a Art Décor surgiu na cidade, juntamente com o sistema de abastecimento de água e esgoto, quadruplicando a população em cerca de treze anos. (MELO, 2014).

Para Fernandes (2011), até os anos 60, Campina Grande aproximou-se do posto de cidade mais importante do estado, já que nesse período despontava como importante polo comercial, industrial e tecnológico, não só do estado, mas também da Região Nordeste, passando a arrecadar mais impostos do que a Capital. No que tange à expansão urbana, a cidade foi reconhecida entre 1960 e 1980 como capital regional do trabalho e do desenvolvimento.

Importante destacar que, para respaldar as lacunas legislativas federais no que se concerne ao parcelamento do solo urbano, foi instituída A Lei de Parcelamento de Solo de $\mathrm{n}^{\circ}$ Lei 6.766, de 19 de dezembro de 1979, que contemplou a ordem urbanística elevando-a à magnitude tal e acabou por direcioná-la à satisfação do interesse social, tornando-a questão de ordem pública. A lei de parcelamento do solo consiste em um grande marco do início da construção da legislação urbanística brasileira, sendo ainda hoje uma das mais importantes normas do setor, tendo ao longo dos anos sofrido algumas alterações.

$\mathrm{Na}$ década de 70 foi instituído em Campina Grande o PPICG (Plano Diretor de Desenvolvimento Integrado de Campina Grande) e foram implantados nessa mesma época dois programas federais de desenvolvimento urbano: O CURA (Comunidade Urbana para Recuperação Acelerada) e o PNCCPM (Programa Nacional para Capitais e Cidades de Porte Médio), que tiveram destaque no desenvolvimento urbano e habitação, com a criação de vias arteriais ligando pontos que seguiram as coordenadas geográficas principalmente do centro às demais regiões como é o caso da Avenida Floriano Peixoto (Figura 02) e a implantação de três grandes conjuntos habitacionais localizados na região Sudoeste, primeira área da cidade beneficiada por esses programas: Severino Cabral, Presidente Médice e Álvaro Gaudêncio, totalizando quatro mil unidades habitacionais, entre 1975 e 1981. (MEDEIROS, 2018). 
Figura 02: Mapa da cidade - Av. Floriano Peixoto liga o centro à região sudoeste

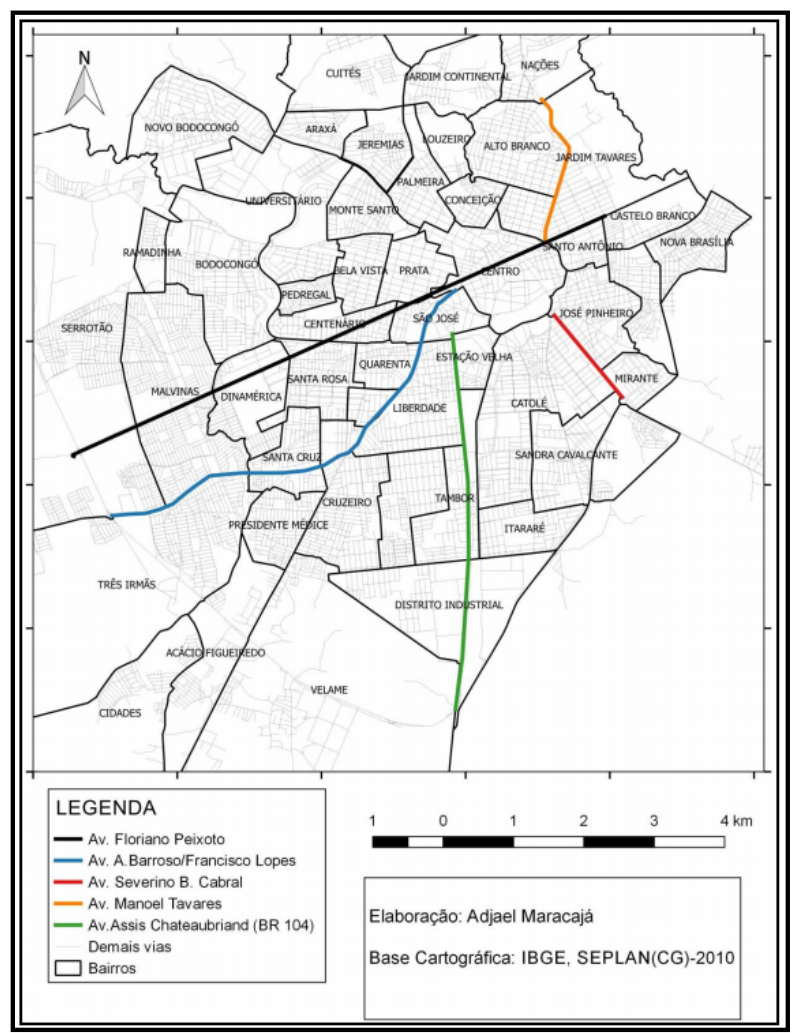

Fonte: (MEDEIROS, 2018)

O conjunto habitacional Álvaro Gaudêncio seria destinado aos servidores estaduais, porém quando foram concluídas as construções, em 1983, faltava infraestrutura mínima para habitação como rede de abastecimento de água, energia e esgoto, reflexo das limitações que tangenciavam as legislações municipais acerca do parcelamento, uso e ocupação do solo. (MEDEIROS, 2018).

Continha 3.300 unidades habitacionais dispostas em 18 mil metros quadrados, implantadas pelo governo do estado em parceria com a CEHAP (Companhia Estadual de Habitação Popular) na década de 80.Nesse ínterim, em 1979 surge a Lei Federal de Parcelamento do solo $n^{\circ} 6766$, com imposição de controles mais rigorosos da ocupação do solo, porém destinava aos municípios a incumbência de controlar alguns quesitos importantes, como a porcentagem de áreas verdes e equipamentos comunitários, além de seções transversais de vias públicas, fazendo com que suas posturas não tivessem tanta relevância para Campina Grande, que ainda carecia de legislações municipais de caráter urbanístico. (MEDEIROS, 2018)

Marca-se, então, o início da expansão urbanística da cidade sob o pressuposto da ocupação territorial desordenada, sobretudo na região sudoeste.Medeiros (2018) relata que as casas do conjunto habitacional Álvaro Gaudêncio não foram entregues aos servidores, e 
mediante a falta de providências dos órgãos competentes para a conclusão definitiva da obra e o déficit habitacional que assolava a época, em 23 de março do mesmo ano, aconteceu a ocupação deste conjunto habitacional.

Esse conjunto habitacional passou a ser bairro oficialmente em 1987, através da Lei Municipal número 1.542, que o denominou de Malvinas. É um dos mais populosos da cidade. Segundo IBGE (2020) apresenta um número superior a 90 mil habitantes. A identificação dos problemas sociais e estruturais encontrados são reflexos da forma como se deu seu crescimento irregular e desordenado, sem áreas verdes e equipamentos comunitários para o convívio social, tendo em vista que o lazer é um dos fatores determinantes do processo de urbanização e sua lacuna relaciona-se intimamente com a falta de inclusão na dinâmica social e cultural da sociedade.

Nessa conjectura, os espaços utilizados pela comunidade adquirem um significado próprio, revelando o sentimento de luta e conquista presente nos moradores do bairro Malvinas, deram início a movimentos por melhores condições de vida no que se concerne ao direito à cidade, consequência da inexistência de políticas urbanas capazes de observar os aspectos do desenvolvimento social-cultural.

A existência dos espaços públicos depende do significado que a comunidade lhe concede, o qual muitas vezes está relacionado com as formas de apropriação e o uso no plano da vida cotidiana, gerados ao longo do tempo, tornando-se referencial para o lugar. Esse referencial delineia a forma como os moradores do bairro em foco agem em busca de seus ideais coletivos reivindicando seus direitos. (MEDEIROS, 2018, apud RECHIA, 2003, p.14).

Após alguns meses de conflito, o governo estadual cedeu o direito das casas às famílias mediante pagamento de prestações, porém a infrastrutura mínima para atender aos moradores só fora implantada cinco anos depois, no seu segundo mandato do governo estadual, O nome Malvinas veio do conflito militar na mesma época da invasão, o das llhas Falkland, popularmente conhecidas como Ilhas Malvinas, localizadas ao extremo sul da América Latina. (MEDEIROS, 2018).

Enquanto isso, o Brasil celebrava sua vitória na incessante luta pelo direito cidadão, através do federalismo cooperativo com a Constituição de 1988 aos sistemas de políticas públicas (Texto constitucional promulgado em 5 de outubro de 1988, com as alterações determinadas pelas Emendas Constitucionais de Revisão nos 1 a 6/94, pelas Emendas Constitucionais nos $1 / 92$ a 91/2016 e pelo Decreto Legislativo no 186/2008), buscando a orientação da democrática descentralizadora e firmando a autonomia municipal, especialmente em relação às diretrizes para o desenvolvimento urbano nacional.

Nesse contexto, após uma década sem relevantes marcos urbanísticos, em 8 de Janeiro de 1996, foi instituído o PDCG (Plano Diretor de Campina Grande) através da Lei Municipal $n^{\circ} 3.236$, um importante instrumento na política de desenvolvimento e expansão do município, tendo como finalidades principais ordenar suas funções socioespaciais e dividir o 
território em rural e urbano, sendo este último subdividido em quatro subzonas: adensáveis, de ocupação indicada, não adensáveis e de expansão.Sua revisão ocorreu em 2006, sem alterações de grande relevância.

\begin{abstract}
Pensar em um Direito Urbanístico significa pensar na função do Direito de dotar o Poder Público de novos instrumentos jurídicos, no respeito ao princípio da legalidade, para disciplinar e ordenar a realidade em benefício do interesse social, ou seja, atuar através do Direito no espaço e realidade urbanos, dotando o Poder Público de mecanismos de atuação e gestão da cidade, visando sua sustentabilidade e uma melhor condição de vida, moradia, infraestrutura, para os seus habitantes, e, ao mesmo tempo, criar canais de participação e gestão democrática no que concerne às questões urbanas. (DORNERLAS, 2011, p.4).
\end{abstract}

O século $X X I$, sob os parâmetros do desenvolvimento urbano, tem seu marco inicial através da sanção do Estatuto da Cidade no dia 10 de julho de 2001, lei regulamentadora dos artigos 182 e 183 da Constituição Federal de 1988e sua importância se deve principalmente por se tornar a referência central para a devida compreensão e interpretação das muitas e complexas questões jurídicas intrínsecas ao processo de uso, ocupação e parcelamento do solo urbano, bem como para dar suporte jurídico adequado às práticas de gestão urbana.

\title{
2. A EXPANSÃO NA REGIÃO SUDOESTE DE FORMA MENOS DESORDENADA E OS EMPREENDIMENTOS DE HABITAÇÃO DE INTERESSE SOCIAL
}

Até meados de 2008, com o ordenamento urbanístico refletido pelo Plano Diretor e sua revisão, o bairro Malvinas, sobretudo a região sudoeste da cidade, agregou oito conjuntos habitacionais, cinco da CEHAP e três da Caixa Econômica Federal, além de um loteamento particular com mais de 300 casas, porém ainda com limitações legais de parcelamento, uso e ocupação do solo. (MEDEIROS, 2018).Nesse contexto, como subterfúgio às lacunas que o município enfrentava no que tangenciavam ainda às normativas urbanísticas, em 24 de Setembro de 2009, foi instituído o Código Municipal de Defesa do Meio ambiente, com a Lei Complementar $n^{\circ} 042$, com posturas mais rígidas nessa seara e uma atenção especial às questões ambientais nos pressupostos urbanísticos.

O cenário nacional enfrentava nessa mesma época sérios problemas de ordens socioeconômicas e habitacionais. Dentro da expectativa de melhorias, o governo federal implantou através do Decreto 6.025, de 22/01/2007, o Programa de Aceleração do crescimento (PAC), constituído de medidas de estímulo ao investimento privado, ampliação dos investimentos públicos em infraestrutura e voltadas à melhoria da qualidade do gasto público e ao controle da expansão dos gastos correntes no âmbito da Administração Pública Federal. Como benefícios para a região sudoeste de Campina Grande, podem-se destacar a adequação do trecho Campina Grande (BR-104/PB - divisa PB/PE), duplicação do contorno de Campina Grande (BR-230/PB), além de empreendimentos de urbanização em ocupações irregulares no Bairro Novo Horizonte. O PAC foi destituído em 2019 pelo Governo Federal. 
O déficit habitacional nacional entre 2007 e 2009 estava grande, foi então que o Governo Federal sancionou O Programa Minha Casa Minha Vida (PMCMV), criado por meio da Medida Provisória $n^{\circ} 459$, de 25 de março de 2009, a qual posteriormente foi convertida na Lei Ordinária No 11.977, de 7 de julho de 2009, que teve como objetivo declarado na lei, criar mecanismos de incentivo à produção e à aquisição de novas unidades habitacionais (UH) pelas famílias com baixa renda, residentes em quaisquer municípios brasileiros.(HIROMOTO, 2018). Na atualidade, esse programa chama-se Casa Verde e Amarela e sua conjectura está em processo de reformulações.

De modo geral, os principais atores envolvidos na operação do Programa foram: a União (representada pelo Ministério das Cidades, Ministério da Fazenda, Ministério do Planejamento Orçamento e Gestão), a Caixa Econômica Federal (CEF), o Banco do Brasil (BB), as construtoras e incorporadoras, as entidades organizadoras e, por fim, o poder executivo subnacional (representado pelos estados, municípios e distrito federal). (HIROMOTO, 2018).

De imediato, com o lançamento desse programa, muitos questionamentos nas esferas positivas e negativas foram impostos à população, porém foi evidente que seu caráter propositivo de fornecer moradia aos menos favorecidos veio como instrumento fundamental. $O$ período entre 2009 e 2019 foi determinante para que esse programa pudesse revelar seus pros e contras, em abrangentes cenários, desde a localização desses empreendimentos, o direito à cidade, questionamento de segregação à transparência nas modalidades políticas de implementação.

Para Hiromoto (2018), além de beneficiar a classe mais abastada, o Estado tinha como objetivo o "aquecimento da economia" via grandes construtoras e bancos. A política habitacional funcionou, predominantemente, como simulacro da produção capitalista do espaço, através da construção em macro escala de habitações que, em grande parte, não atendiam às necessidades dos mais pobres.Não se teve em vista a necessidade de moradia, mas os lucros que puderam ser angariados a partir dessa necessidade. Contudo, a necessidade de um abrigo, de um lar, é o aspecto mais importante a ser levado em conta, nesse caso. Porém, nas cidades brasileiras o que se verificava era o constante reforço da casa enquanto uma mercadoria.

De acordo com Maricato (2018), não há solução para o problema habitacional sem intervir em aspectos fundamentais que embasam o poder na sociedade brasileira como o patrimonialismo e a captação das rendas imobiliárias. Hiromoto (2018) compactua com o mesmo pensamento, ao afirmar que a maioria dos moradores das cidades não consegue participar das decisões sobre seu cotidiano e pensar sobre os problemas que os afligem.

Esse cenário não foi diferente na realidade da região sudoeste de Campina Grande entre os anos de 2013 e 2019, que se expandiu ligeiramente com a implantação de alguns empreendimentos MCMV para famílias com renda de até $\mathrm{R} \$ 1.800,00$, a chamada faixa 1 , com 
é o caso das 1948 unidades habitacionais unifamiliares inseridas nos loteamentos Raimundo Suassuna e Acácio Figueiredo, além das 1984 unidades multifamiliares construídas no Conjuntos Major Veneziano I, II, III e IV, nos bairros Três Irmãs e Cidades e do Complexo Aluízio Campos, com 4100 unidades habitacionais, sendo 3200 unidades unifamiliares e 900 unidades multifamiliares, localizadas no bairro Ligeiro, dados esse coletados em entrevista presencial do autor desse artigo com a Coordenação de Planejamento Urbano de Campina Grande, em agosto de 2020.

Ainda de acordo com essa entrevista, alguns loteamentos privados foram implantados na região sudoeste com características de bairros planejados, como o Loteamento Portal Sudoeste (figura 03), com mais de 2000 lotes, enriquecendo o cenário urbanístico socioeconômico da região no que tange a implantação de equipamentos comunitários (com investimentos públicos), praças e uso misto da ocupação do solo urbano, porém ainda com as mesmas características dos demais loteamentos ali implantados no que concerne às áreas lotes de $160,00 \mathrm{~m}^{2}$, potencializando então pequenos construtores a implantarem edificações unifamiliares e multifamiliares com um padrão um pouco mais elevado, cujas aquisições foram provenientes do programa MCMV faixa 1,5, para famílias com faixa de renda máxima de $R \$$ $2.600,00$.

Figura 03: Vista aérea do Loteamento Portal Sudoeste

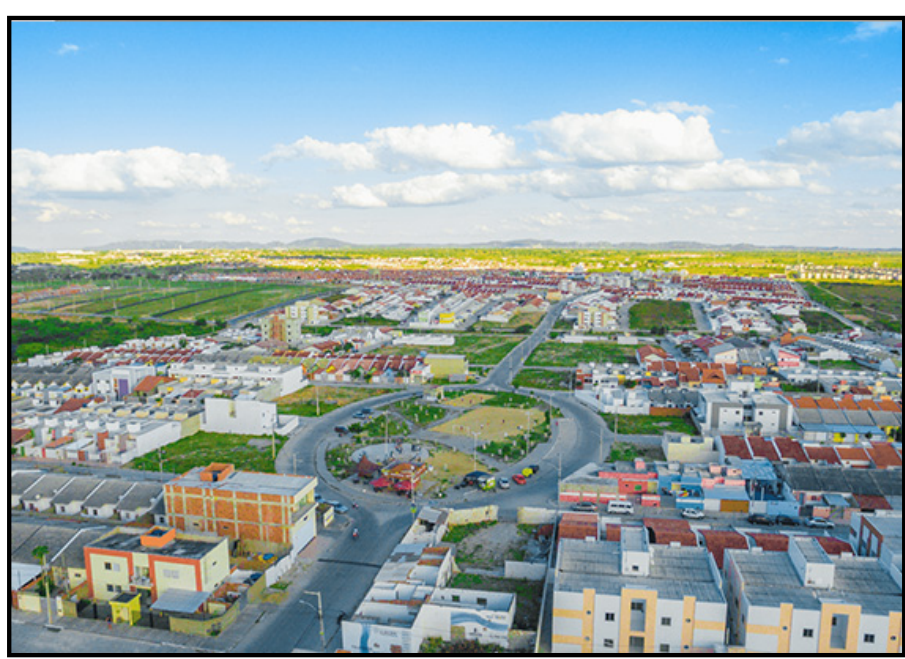

Fonte: www.casasportalsudeoeste.com.br

De acordo com a última revisão do Plano Diretor de Campina Grande de 2006, a implantação desses conjuntos habitacionais se deu na Zona de Expansão Urbana prevista pelo Plano, afirmando que:

[...] onde o uso e a ocupação do solo destinam-se ao crescimento da cidade, associado a essas definições do Plano Diretor para as áreas de expansão, soma-se ainda fatores importantes como a baixa especulação imobiliária, baixo preço da terra ainda não urbanizada e a tentativa de evitar a mistura urbana. (Campina Grande, Lei Complementar 033/2006). 
Porém, analisando os dados coletados e tendo como pressuposto o Plano Diretor vigente, pode-se compreender que há uma dissonância na realidade verificada atualmente na cidade de Campina Grande, especificamente na expansão da região sudoeste, principalmente no que se refere aos terrenos privados ainda não urbanizados (parcelados e/ou loteados), que estão supervalorizados e são alvos de especulação imobiliária, evidenciando novamente a urgência da nova revisão do plano diretor para nortear esse antagonismo ocupacional, podendo-se elucidar, como consequência, o atual cenário de centralidade, segregação e gentrificação.

\begin{abstract}
O direito à cidade não pode ser concebido simplesmente como um direito individual. Ele demanda um esforço coletivo e a formação de direitos políticos coletivos ao redor de solidariedades sociais. No entanto, o neoliberalismo transformou as regras do jogo político. A governança substituiu o governo; os direitos e as liberdades tem prioridade sobre a democracia; a lei e as parcerias público-privadas, feitas sem transparência, substituíram as instituições democráticas; a anarquia do mercado e do empreendedorismo competitivo substituíram as capacidades deliberativas baseadas em solidariedades sociais". (HARVEY, 2013, apud SANTOS, 2020, p.32)
\end{abstract}

Nesse ínterim, aguardando a nova revisão do plano diretor que possa impor mais rigidez de caráter ocupacional do solo e de direito à moradia digna, foi sancionado em 2015 o Plano Municipal de Mobilidade Urbana, através da Lei Complementar $n^{\circ} 004$, com destaque para o aspecto de acessibilidade, impondo seções transversais de vias públicas com no mínimo 12,00 metros, sendo 2,50 metros de calçadas, exigências essas de extrema importância para um parcelamento do solo que proporcione melhor qualidade de vida e inclusão.

\title{
3. EXPANSÃo dA REGIÃO SUDOESTE SOB A ÓtICA DA CENTRALIDADE, SEGREGAÇÃO E GENTRIFICAÇÃO
}

Nos últimos dez anos, a região sudoeste foi beneficiada com investimentos públicos e privados no que diz respeito à infraestrutura, pelo fato de concentrar muitos empreendimentos com habitações de interesse social e ter sua localização privilegiada, por estar margeada pelas rodovias federais BR 104 e a BR 230. Essa valorização do solo despertou interesse de muitas loteadoras, construtoras e incorporadoras, que implantaram loteamentos, condomínios verticais, condomínios horizontais de lotes com padrão elevado, além de edificações destinadas a comércios / serviços, pólos industriais e tecnológico, configurando-se, assim, uma região de uso misto, com características de centralidade.

Para Oliveira (2017), a centralidade vai além da delimitação física/espacial do Centro, materializando-se através de fluxos. Sendo assim, pode-se afirmar que a centralidade pode ser observada sob diversas materializações, como, por exemplo, não concorrência de empreendimentos de grandes capitais (Shopping Center, atacados, polos industriais, polos 
estudantis) localizados em pontos da estrutura urbana, como também a partir da emergência de novas áreas centrais, ou seja, bairros, ruas, vias ou áreas denominadas Centros de Bairro ou Subcentros.

Outros pontos que pode-se observar como consequências do modo pelo qual a região sudoeste da cidade se expandiu e a segregação e a fragmentação, com relação direta à centralidade (figura 04), onde a paisagem urbana abriga classes sociais desiguais, principalmente pelo fato de que sua ocupação territorial deu-se inicialmente por moradias populares no Conjunto Habitacional Álvaro Gaudêncio (o atual bairro Malvinas) e com o processo de urbanização e expansão outros tipos de moradias com melhores padrões surgindo.

Figura 04: Malvinas como exemplo de novo centro de bairro

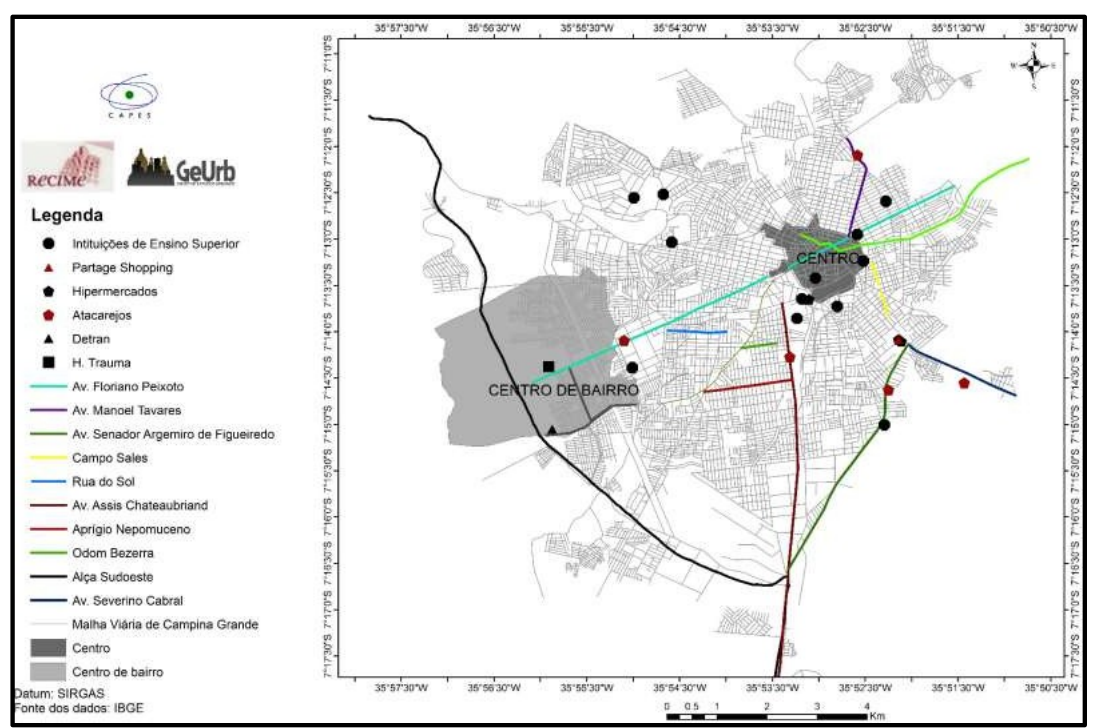

Fonte: (OLIVEIRA, 2017)

Esse aspecto também se verifica no que diz respeito à implantação dos empreendimentos de habitação de interesse social oriundos dos programas do Governo Federal, havendo um paradoxo: na decisão de onde construí-las, pois implantar esses empreendimentos em áreas bem com boa infraestrutura e equipadas, perto de centros de comércio e serviços, polos de emprego e equipamentos de lazer, implica em assumir um ônus elevado, considerando-se o valor da área urbanizada. Por outro lado, o custo social de implantação de infraestrutura decorrente de empreendimentos em localizações distantes, em geral não é contabilizado como parte do custo do empreendimento, onerando o setor público, que raramente impõe regras para a recuperação de pelo menos parte desse gasto. (ARAUJO; NASCIMENTO, 2018).

Outra característica inerente, em face às transformações urbanísticas ocorridas nessa região é a existência de muitos terrenos privados vazios supervalorizados. Nos últimos anos houve forte especulação imobiliária em decorrência desse aspecto, aquecendo o mercado e a construção de condomínios horizontais fechados para atender uma população da classe 
média, mudando ainda mais o cenário da ocupação do solo da região sudoeste da cidade e despertando a atenção para o fenômeno urbano chamado de gentrificação.

O ponto crucial sobre a gentrificação é que ela envolve não apenas uma mudança social, mas também, na escala de bairro, uma mudança física no parque habitacional e uma mudança econômica na terra e mercados da habitação. (SMITH, 1987, p. 463, apud MEDEIROS, 2018, p.84).

Apesar da apropriação e vantagens do entorno serem medidas compensatória para acentuar parte da valorização perdida pela distância do centro, percebe-se que esses condomínios horizontais fechados sempre anunciam a "vantagem" do curto tempo percorrido para a área central e para os serviços da cidade, demonstrando que a força de valorização possibilitada pelos serviços do centro e subcentros da cidade ainda pesa como um atributo importante, graças à ligação pelas grandes vias de acesso (MEDEIROS, 2018), como é o caso da Avenida Marechal Floriano Peixoto, que perpassa em todos esses condomínios horizontais ao centro da cidade.

Partindo desse princípio, pode-se observar a lacuna que a nova revisão do plano diretor municipal traduz na expansão da região sudoeste da cidade, sem parâmetros específicos de zoneamento, parcelamento, uso e ocupação do solo. A mesma entrevista realizada no mês de agosto de 2020, com a Coordenação de Planejamento Urbano, afirmou que a prefeitura, através da Secretaria de Planejamento empossou no dia 20 de Dezembro de 2019, os membros da Comissão Especial de Revisão e Alteração do Plano Diretor de Campina Grande, conforme determinou o Decreto 4.443/2019. Devido a epidemia do Corona Vírus, os resultados ainda não foram alcançados e não há previsão para seu término.

Medeiros, 2018 elucida um pensamento homogêneo comparado aos demais autores que consubstanciaram os conceitos dessa pesquisa acerca de centralidade, segregação e gentrificação, destacando que apesar da fraca capacidade de mobilização anticapitalista, do seu caráter limitado e fugaz, a verdade é que, não raras vezes, os novos movimentos sociais urbanos comportam inovação social e política, encetada por vanguardas poderosas, pois visam às mudanças "transformativas" e as novas respostas no que se tange ao poder na sociedade contemporânea, sobretudo quando se organizam a partir de "espacialidades de resistência" multiescalares, convergindo veementemente para o relevante aspecto das políticas urbanas em face à expansão, que é o direito à cidade.

\section{CONSIDERAÇÕES FINAIS}

A presente pesquisa buscou abordar o processo de expansão urbana da cidade de Campina Grande com foco na região sudoeste nos âmbitos de parcelamento, uso e ocupação de solo e os resultados às problemáticas abordadas foram determinantes para o alcance dos objetivos propostos. 
Em face ao cenário exposto, pode-se concluir que a expansão da região sudoeste iniciou-se a partir de lutas pelo direito á cidade e moradia digna, tendo como protagonista principal o déficit habitacional. Nesse contexto destaca-se a contribuição do processo inicial de urbanização do Conjunto Álvaro Gaudêncio, que através de lutas de classes, pôde despertar o olhar das políticas públicas norteadoras das legislações urbanísticas, ganhando características de área predominantemente urbana, pelos grandes investimentos em infraestrutura e habitação nessa região.

A limitação maior encontrada no decorrer da pesquisa foi conseguir informações acerca da nova revisão do plano diretor da cidade, que está em fase de desenvolvimento e será de suma importância para entender e descobrir quais serão suas premissas e perspectivas no que tange às áreas de expansão, uma vez que a região sudoeste está em constante desenvolvimento, mas há ainda muitos vazios urbanos, caracterizados por terrenos privados ociosos, com seu entorno urbanizado, tornando-os mais valorizados e especulados.

\section{REFERÊNCIAS}

AGUIAR, Joaquim Castro. Direito da Cidade. Rio de Janeiro: Editora Renovar, 1996. BRASIL. Lei no 10.257, de 10 de julho de 2001 (Estatuto da Cidade). Brasília: Presidência da República, 2001.

ARAÚJO. Miguel Etinger de Araújo Junior. Algumas considerações sobre o Plano Diretor dos municípios e sua importância no processo de construção da cidadania e da democracia. Revista do Direito Público. Londrina, PR. V. 1, N. 1, p. 45-62. 2006.

BONDUKI, Nabil. Origens da habitação social no Brasil: Arquitetura moderna, Lei do Inquilinato e difusão da casa própria. São Paulo: Estação Liberdade: FAPESP, 1998.

BRASIL. Legislação. Lei n. 10.257, de 10 de julho de 2001. Regulamenta os arts. 182 e 183 da Constituição Federal, estabelece diretrizes gerais da política urbana e dá outras providências. Disponível em http://www.planalto.gov.br. Acessado em 10 de Setembro de 2020.

CABRAL, Murilo Bruno. Coordenador de Planejamento Urbano - Secretaria de Planejamento, Prefeitura Municipal de Campina Grande - PB. Depoimento[Agosto,2020]. Entrevistador: Davi Mendes Agra. Pós graduando em Planejamento Urbano e Gestão de Cidades - UNIPE, 2020.

CAMPINA GRANDE, Prefeitura Municipal de. Campina Grande - PB. 1996. Plano Diretor Municipal. Disponível em: www.pmcg.org.br. Acessado em 01 de Outubro de 2020.

CAMPINA GRANDE, Prefeitura Municipal de. Campina Grande - PB. 2006. Plano Diretor Municipal. Disponível em: www.pmcg.org.br. Acessado em 01 de Outubro de 2020.

CAMPINA GRANDE, Prefeitura Municipal de. Campina Grande - PB. 2009. Lei Complementar 042 - Código de defesa do Meio Ambiente. Disponível em: www.pmcg.org.br. Acessado em 02 de Outubro de 2020.

CAMPINA GRANDE, Prefeitura Municipal de. Campina Grande - PB. 2015. Plano de Mobilidade de Campina Grande. Disponível em: www.pmcg.org.br. Acessado em 03 de Outubro de 2020. 
DORNELAS, Henrique Lopes. 2011. O Direito Urbanístico e a importância do Plano Diretor Municipal. Rio de Janeiro, RJ. Disponível em www.revista.uniabeu.edu.br.Acessado em 01 de Outubro de 2020.

FERNANDES, Silvana Torquato. 2011. Campina Grande, PB. Uma outra representação da modernização em Campina Grande: a cidade nas páginas do Diário da Borborema (1960/1980). Disponível em www.scielo.org. Acessado em 16 de Setembro de 2020.

GOMES, Manoel W. Queiroz. Expansão Urbana: Um estudo sobre o processo e suas conseqüências. 2012. São Paulo, SP. Disponível em www.webastigos. Acessado em 02 de Setembro de 2020.

HIROMOTO, Martha Hanae, 2018. Análise de três dimensões do Programa Minha Casa Minha Vida: Expansão urbana, infraestrutura de saneamento e emprego. 2018. São Paulo SP. Disponível emwww.bibliotecadigital.fgv.br. Acessado em 03 de Outubro de 2020.

MARICATO, Ermínia. A produção capitalista da casa (e da cidade) no Brasil industrial. São Paulo: Alfa-omega, 1982.

MARICATO, Erminia. A questão urbana no Brasil hoje. Brasília, 2012. Disponível em: www.erminiamaricato.net/2012/11/. Acessado em 28 de agosto de 2020

MARICATO, Ermínia; Akaishe, Ana Gabriela. 2018. O Brasil na era das cidades-condomínio. Disponível em www.jornalggn.com.br/cidadeser. Acessado em 03 de Outubro de 2020.

MAURO, Normando M. Barros Filho; JOÃO, Batista M. da Silva Júnior; JADE, Felizola de Brito. 2016. Salvador, BA. Lacunaridade intra urbana: Análise dos espaços livres da cidade de Campina Grande - PB. Disponível em www.scielo.org. Acessado em 15 de Setembro de 2020.

MEDEIROS, Mateus Araújo de. 2018. Campina Grande - PB. Expansão urbana e a segregação sócioespacial presentes no bairro Malvinas, Conjunto Álvaro Gaudêncio: Políticas públicas de moradia $\mathbf{x}$ condomínios privados. Disponível em www.scielo.org. Acessado em 16 de Setembro de 2020.

MEDEIROS, Sara Raquel F. Queiroz de. Natal, RN. 2018. Segregação e gentrificação: os conjuntos habitacionais em Natal - RN. Disponível em www.repositorio.ufrn.br. Acessado em 18 de Outubro de 2020.

MELO, Maurício. 2014. João Pessoa, PB. Reforma urbana mudou o Centro na década de 1930. Disponível em: www.jornaldaparaiba.com.br/campina150. Acessado em 16 de Setembro de 2020.

MENDONÇA, Rafael da Mota. 2020. A formação de consensos da realização de políticas públicas de regularização fundiária: A Lei 13.465/2017 e a gestão democrática das cidades. Rio de Janeiro - RJ. Disponível em www.e-publicacoes.uerj.br. Acessado em 02 de Outubro de 2020.

MOTTA, Luana. 2011. A questão da habitação no Brasil: políticas públicas, conflitos, urbanos e o direito à cidade. São Paulo - SP. Disponível em: www.scielo.org . Acesso em: 12 de setembro de 2020.

NASCIMENTO, Alexandre Sabino do.; ARAÚJO, Caline de Mendes. 2018. Do BNH ao PMCMV: Uma Análise espaço-temporal dos programas / projetos habitacionais desenvolvidos em campina Grande - PB e a negação do direito à cidade. Disponível em www.scielo.org. Acessado em 15 de Outubro de 2020. 
OLIVEIRA, Taynan Araújo de. Centralidades e novas áreas centrais em Campina Grande Paraíba, Dissertação apresentada ao programa de pós-graduação em Geografia da Universidade Federal de Campina Grande (PPGG/UFPB) como requisito para obtenção de Mestre em Geografia. João Pessoa,PB.2017.Disponívelem:https://repositorio.ufpb.br/jspui/bitstream.Acesso em 25 de Agosto de 2020.

PENA, Rodolfo F. Alves. 2015. Recife, PE. Urbanização no Nordeste. Disponível em: https://brasilescola.uol.com.br/brasil/a-urbanizacao-nordeste.htm. Acessado em 15 de setembro de 2020.

REPÚBLICA, Presidência da. Brasília - DF. 2008. Texto constitucional promulgado em 5 de outubro de 1988, com as alterações determinadas pelas Emendas Constitucionais de Revisão nos 1 a 6/94, pelas Emendas Constitucionais nos 1/92 a 91/2016 e pelo Decreto Legislativo no 186/2008. Disponível em www.senado.leg.br. Acessado em 01 de Outubro de 2020.

REPÚBLICA, Presidência da. 2001. Estatuto da cidade, Lei $\mathbf{n}^{\circ} \mathbf{1 0 . 2 5 7}$, de 10 de Julho de 2001. Brasília - DF. Disponível em: www.planalto.gov.br. Acessado em 01 de Outubro de 2020.

REPÚBLICA, Presidência da. 2001. Decreto $n^{\circ} 6.025$ de 22 de Janeiro de 2007, Programa de Aceleração do Crescimento - PAC. 2007. Brasília - DF. Disponível em: www.planalto.gov.br. Acessado em 02 de Outubro de 2020.

REPÚBLICA, Presidência da. 2009. Medida Provisória $n^{\circ}$ 459, de 25 de Março de 2009, Dispõe sobre o Programa Minha Casa, Minha Vida - PMCMV, a regularização fundiária de assentamentos localizados em áreas urbanas, e dá outras providências.2009. Brasília - DF. Disponível em: www.planalto.gov.br. Acessado em 02 de Outubro de 2020.

SANTOS, Jouberte M. Leandro. 2020. Hegemonia do Planejamento Urbano Estratégico e o Discurso Contra-Hegemônico do Direito à Cidade. Recife - PB. Disponível em www.periodicos.ufv.br. Acessado em 10 de Outubro de 2020.

SOBRINHO, João Alves. História de Campina Grande em versos. Campina Grande: Academia Brasileira de Literatura de Cordel, 2004.

VILLAÇA, Flávio. Espaço intra-urbano no Brasil. São Paulo: Studio Nobel: FAPESP: Lincoln Institute, 2001. 